\title{
Morphometric variability among the species of the Sordida subcomplex (Hemiptera: Reduviidae: Triatominae): evidence for differentiation across the distribution range of Triatoma sordida
}

Julieta Nattero ${ }^{1,2^{*}}$, Romina Valeria Piccinali ${ }^{1,2}$, Catarina Macedo Lopes ${ }^{3}$, María Laura Hernández ${ }^{4}$, Luciana Abrahan ${ }^{4}$, Patricia Alejandra Lobbia ${ }^{5}$, Claudia Susana Rodríguez ${ }^{6}$ and Ana Laura Carbajal de la Fuente ${ }^{1,2}$

\begin{abstract}
Background: The Sordida subcomplex (Triatominae) comprises four species, Triatoma garciabesi, T. guasayana, T. patagonica and T. sordida, which differ in epidemiological importance and adaptations to human environments. Some morphological similarities among species make taxonomic identification, population differentiation and species delimitation controversial. Triatoma garciabesi and T. sordida are the most similar species, having been considered alternatively two and a single species until T. garciabesi was re-validated, mostly based on the morphology of male genitalia. More recently, T. sordida from Argentina has been proposed as a new cryptic species distinguishable from T. sordida from Brazil, Bolivia and Paraguay by cytogenetics. We studied linear and geometric morphometry of the head, wings and pronotum in populations of these species aiming to find phenotypic markers for their discrimination, especially between $T$. sordida and T. garciabesi, and if any set of variables that validates T. sordida from Argentina as a new species.

Results: Head width and pronotum length were the linear variables that best differentiated species. Geometric morphometry revealed significant Mahalanobis distances in wing shape between all pairwise comparisons. Triatoma patagonica exhibited the best discrimination and T. garciabesi overlapped the distribution of the other species in the morphometric space of the first two DFA axes. Head shape showed differentiation between all pairs of species except for T. garciabesi and T. sordida. Pronotum shape did not differentiate T. garciabesi from T. guasayana. The comparison between T. garciabesi and T. sordida from Argentina and T. sordida from Brazil and Bolivia revealed low differentiation based on head and pronotum linear measurements. Pronotum and wing shape were different between T. garciabesi and T. sordida from Brazil and Bolivia and T. sordida from Argentina. Head shape did not differentiate T. garciabesi from T. sordida from Argentina.

(Continued on next page)
\end{abstract}

\footnotetext{
* Correspondence: julietanattero@ege.fcen.uba.ar

${ }^{1}$ Facultad de Ciencias Exactas y Naturales, Departamento de Ecología, Genética y Evolución/Laboratorio de Eco-Epidemiología, Universidad de Buenos Aires, Ciudad Autónoma de Buenos Aires, Buenos Aires, Argentina ${ }^{2}$ CONICET - Universidad de Buenos Aires, Instituto de Ecología, Genética y Evolución de Buenos Aires (IEGEBA), Ciudad Autónoma de Buenos Aires, Buenos Aires, Argentina

Full list of author information is available at the end of the article
} 
(Continued from previous page)

Conclusions: Wing shape best delimited the four species phenotypically. The proposed cryptic species, T. sordida from Argentina, differed from T. sordida from Brazil and Bolivia in all measured shape traits, suggesting that the putative new species may not be cryptic. Additional studies integrating cytogenetic, phenotypic and molecular markers, as well as cross-breeding experiments are needed to confirm if these three entities represent true biological species.

Keywords: Sordida subcomplex, Triatoma garciabesi, Triatoma guasayana, Triatoma patagonica, Triatoma sordida, Head, Pronotum, Wing, Linear morphometrics, Geometric morphometrics

\section{Background}

The subfamily Triatominae (Reduviidae) consists of 151 described species grouped in 15 genera, widely and mainly distributed in the American continent, including the Caribbean Islands (reviewed in [1]). All the species of this subfamily are obligate haematophagous that can transmit Trypanosoma cruzi Chagas, 1909, the etiological agent of Chagas disease [1]. Triatoma is the most conspicuous genus within the subfamily, with 84 species grouped in 8 complexes and 14 subcomplexes [1]. The Sordida subcomplex traditionally included four species: Triatoma sordida Stål, 1859; T. patagonica Del Ponte, 1929; T. guasayana Wygodzinsky \& Abalos, 1949; and T. garciabesi Carcavallo, Cichero, Martínez, Prosen \& Ronderos, 1967, with differences in their distribution areas (Figs. 1 and 2a), epidemiological importance and level of adaptation to the human environment [2]. Triatoma sordida is the species of highest epidemiological importance, considering T. cruzi infection rates and its ability to colonize human-made or modified habitats, mainly chicken coops [3-6]. This species has a wide distribution in Argentina, Uruguay, Paraguay, Bolivia and Brazil (Figs. 1a and 2a). Triatoma garciabesi occupies northwestern and central Argentina (Figs. 1b and 2a), with recent records in southern Bolivia and western Paraguay [7]. It is rare in human habitats and is commonly associated with bird nests in wild environments. However, it has been collected from peridomestic structures like chicken coops $[8,9]$. Triatoma guasayana is found in Argentina, Bolivia and Paraguay (Figs. 1c and 2a); it is sylvatic and invades houses temporally $[8,10]$. Triatoma patagonica is endemic to Argentina; it is mainly sylvatic but has also been found colonizing domiciles and peridomiciliary structures in several Argentine provinces (Figs. 1d and 2a) [11-13]. A detailed taxonomic comparison of T. guasayana, T. patagonica and T. sordida using morphometric measurements, genitalia and antennal structures was presented elsewhere [14].

Triatoma sordida and T. garciabesi exhibit high morphological similarity; they partially overlap in their geographical distribution and were considered a single species until 1967, when T. garciabesi was described based on specimens from central Argentina [15].
However, T. garciabesi and T. sordida were considered synonymous during two decades [16]. In 1998, T. garciabesi was re-validated as a species based on characteristics of microhabitats, male genitalia and cytogenetics [17]. To identify these two species, linear measurements from head and pronotum structures have been traditionally used [18]. In addition, cytogenetic, isoenzyme and molecular studies have shown that Argentine T. sordida populations (T. sordida Arg) differ from those of other areas of its distribution (T. sordida Brazil and Bolivia) [7, $19,20]$. This evidence has led to the recent proposal of considering T. sordida Arg a new species [7].

Linear and geometric morphometry has been widely used as a useful tool to delimit species, subspecies and intraspecific variation within the subfamily Triatominae [21-26]. The most commonly used phenotypic markers to resolve variations in geometric morphometry are those for the wings [27], although markers for the head have also been used effectively in morphometric studies $[21,23]$. For example, wing geometric morphometrics was successfully applied to delimit species within the $T$. brasiliensis [28] and T. dimidiata [29] species complexes, with results being in agreement with those of molecular systematics studies $[30,31]$. To our knowledge, the pronotum, has been used to evaluate the dispersive capacity of other species of the Triatominae $[32,33]$, but not to differentiate closely related species, subspecies or varieties.

Given the morphological similarities of the four species of the Sordida subcomplex, the partial overlapping of their distribution, the differences in their epidemiological importance and the proposal of T. sordida Arg to be considered a new cryptic species, in this work we studied the morphometry of the head, wing and pronotum modules using linear and geometric morphometry variables. We included populations of the four species that cover a broad part of their distribution area in Argentina, Brazil and Bolivia, aiming to find phenotypic markers that distinguish the four species, especially the closest ones, T. sordida and T. garciabesi. Finally, we intended to determine if these modules have some morphological variables that validate the proposal to consider T. sordida Arg a new species. 

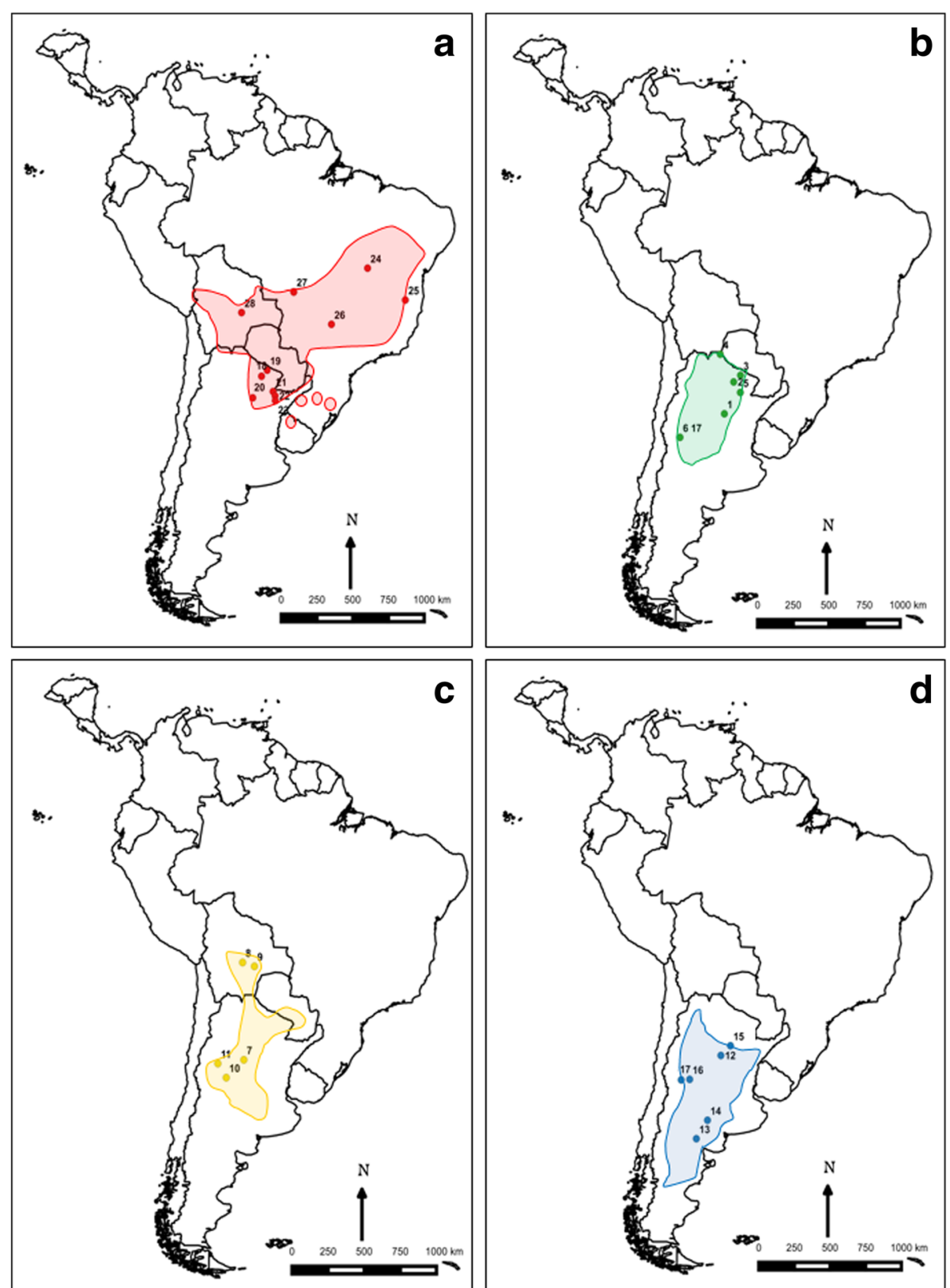

Fig. 1 Geographical maps and locations of the studied populations of Triatoma sordida (a), T. garciabesi (b), T. guasayana (c) and T. patagonica (d). Population codes are as in Table 1. Distribution areas were based on [56]

\section{Methods}

\section{Insects}

A total of 255 males from 28 populations of $T$. garciabesi, T. guasayana, T. patagonica and T. sordida from Argentina, Brazil and Bolivia were included in this study (Table 1, Figs. 1a-d and 2a). Only males were evaluated because their sample size was larger than that of females, and because previous studies suggest sexual dimorphism at least for wing shape in T. sordida [4]. In addition, male individuals from Patiño, Balbuena, Aguirre, El Colchon and most $T$. patagonica populations are the same as those used for recent cytogenetic studies [7]. Only populations with at least four males were included. Most of the populations (23 of 28) were collected from the field, whereas the remaining were colonies with no more than three generations reared in the laboratory (Table 1). Insects from colonies were supplied by the "Centro de Referencia de Vectores (CeReVe)" from the National Health Ministry of Argentina. All populations were collected from peridomestic structures, except those from "Reserva 

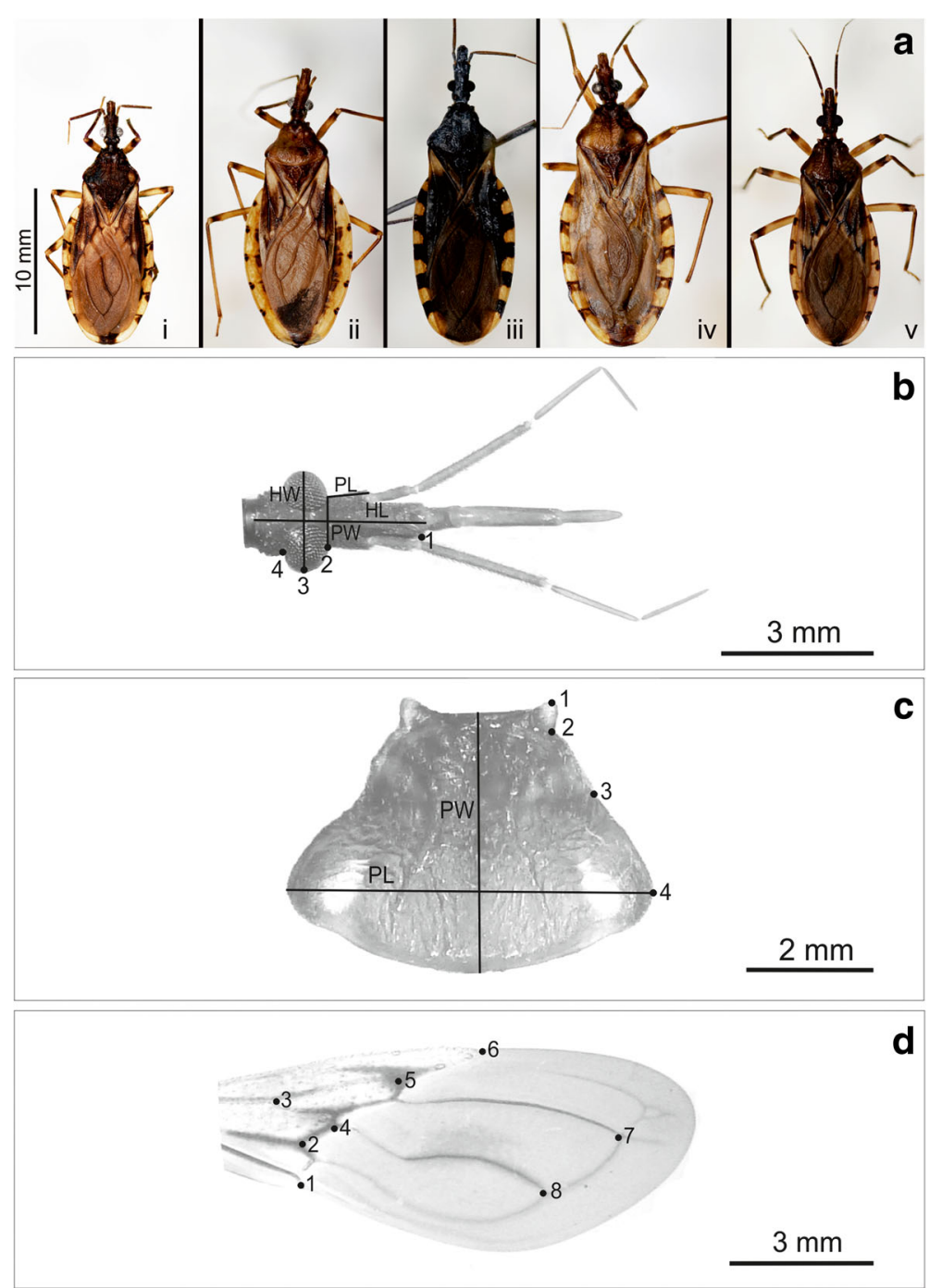

Fig. 2 a Specimens of Triatoma garciabesi (i), T. guasayana (ii), T. patagonica (iii) and T. sordida (iv) from Argentina and T. sordida from Brazil (v). Linear measurements and landmark positions used for the head (b), pronotum (c) and forewings (d) of the four species included in this study. $\mathbf{b}$ Head width $(\mathrm{HW})$, preocular length $(\mathrm{PL})$, head length $(\mathrm{HL})$, preocular width $(\mathrm{PW})$, landmark positions 1-4. c Pronotum width (PW), pronotum length (PL), landmark positions 1-4. d Forewings, landmark positions 1-8

Natural Bosques Telteca", Mendoza Province, which were collected from sylvatic habitats.

In some populations of Triatoma guasayana, brachypterous individuals were reported to occur (J. Espinoza, personal communication). We considered this event and evaluated measures of the pronotum and wings to ensure that brachypterous individuals were not included in this study.

Species were identified following a dichotomous key traditionally used for this purpose [18]. Populations from Patiño and Balbuena were originally identified as $T$. sordida; however, based on cytogenetic and molecular characteristics, these two populations were identified as $T$. garciabesi [7] and were considered as such in this work.
Digital images of ventral and dorsal views of the head, and dorsal views of the pronotum and wings of each individual were taken using a digital camera (Lumix DMC-ZS7, Panasonic) connected to a stereomicroscope (Stemi SV-11, Carl Zeiss). Images include the reference scale.

\section{Linear morphometry}

Images of head and pronotum of each individual were processed using the UTHSCSA ImageTool for Windows ver. 3.00 [34]. Total area $\left(\mathrm{mm}^{2}\right)$ and four linear measurements for the head and two for the pronotum $(\mathrm{mm})$ were taken (Fig. 2b, c). Head length was measured from the base of the head to the anteclipeum and head width corresponded to the maximum external width of head in 
Table 1 Geographical location and coordinates, origin and number of individuals of the studied populations of Triatoma garciabesi, T. guasayana, T. patagonica and T. sordida

\begin{tabular}{|c|c|c|c|c|c|c|c|c|}
\hline Species & Population code & Locality & Province/State & Country & Origin & Latitude & Longitude & No. of individuals \\
\hline \multirow[t]{6}{*}{ T. garciabesi } & 1 & Aguirre & Sgo del Estero & Argentina & Field & -29.52 & -62.17 & 10 \\
\hline & 2 & Balbuena & Chaco & Argentina & 1st LG & -25.64 & -60.93 & 10 \\
\hline & 3 & Patiño & Formosa & Argentina & 1st LG & -24.83 & -60.03 & 5 \\
\hline & 4 & Santa Victoria E & Salta & Argentina & Field & -22.27 & -62.71 & 14 \\
\hline & 5 & El Triangulo & Chaco & Argentina & Field & -26.93 & -60.05 & 12 \\
\hline & 6 & Reserva Telteca & Mendoza & Argentina & Field & -32.38 & -68.06 & 6 \\
\hline \multirow[t]{5}{*}{ T. guasayana } & 7 & Sobremonte & Córdoba & Argentina & Field & -29.76 & -64.05 & 5 \\
\hline & 8 & Mataral & Cochabamba & Bolivia & Field & -18.11 & -64.21 & 14 \\
\hline & 9 & Tita & Santa Cruz & Bolivia & Field & -18.58 & -62.69 & 9 \\
\hline & 10 & San Martín & La Rioja & Argentina & Field & -31.82 & -66.38 & 9 \\
\hline & 11 & Independencia & La Rioja & Argentina & Field & -30.27 & -67.46 & 8 \\
\hline \multirow[t]{6}{*}{ T. patagonica } & 12 & Mitre & Sgo del Estero & Argentina & 3th LG & -29.41 & -62.79 & 9 \\
\hline & 13 & Avellaneda & Río Negro & Argentina & 3th LG & -39.53 & -66.05 & 10 \\
\hline & 14 & Utracán & La Pampa & Argentina & 3th LG & -37.28 & -64.57 & 8 \\
\hline & 15 & El Nochero & Santa Fe & Argentina & Field & -29.68 & -61.51 & 9 \\
\hline & 16 & Santa Rosa & San Luis & Argentina & Field & -32.32 & -66.93 & 12 \\
\hline & 17 & Reserva Telteca & Mendoza & Argentina & Field & -32.38 & -68.06 & 7 \\
\hline \multirow[t]{11}{*}{ T. sordida } & 18 & El Colchón & Chaco & Argentina & Field & -25.61 & -60.36 & 5 \\
\hline & 19 & Crucero Belgrano & Formosa & Argentina & Field & -24.87 & -59.61 & 22 \\
\hline & 20 & El Nochero & Santa Fe & Argentina & Field & -29.68 & -61.51 & 4 \\
\hline & 21 & Corrientes & Corrientes & Argentina & Field & -27.47 & -58.83 & 5 \\
\hline & 22 & San Miguel & Corrientes & Argentina & Field & -28.00 & -58.57 & 5 \\
\hline & 23 & San Roque & Corrientes & Argentina & Field & -28.57 & -58.54 & 5 \\
\hline & 24 & Combinado & Tocantins & Brazil & Field & -12.51 & -46.33 & 13 \\
\hline & 25 & Itaobim & Mina Gerais & Brazil & Field & -16.34 & -41.33 & 13 \\
\hline & 26 & Paranaiba & Mato Grosso & Brazil & Field & -19.29 & -51.11 & 12 \\
\hline & 27 & Várzea Grande & Mato Grosso & Brazil & Field & -15.38 & -56.10 & 9 \\
\hline & 28 & Santa Cruz & Santa Cruz & Bolivia & Field & -17.87 & -63.00 & 5 \\
\hline
\end{tabular}

Abbreviation: $L G$ laboratory generation

dorsal view. Preocular length was measured from the base of the anteniferous tubercules to the eyes and preocular width was measured at the anterior base of eyes. Pronotum length and pronotum width were the maximum length and width, respectively. Head width, pronotum length, and head and pronotum area did not show a normal distribution and were normalized using $\log _{10}$ transformation for statistical analysis.

\section{Geometric morphometry}

A landmark-based approach was applied to study geometric morphometrics of heads, pronotums and right forewings. Four coplanar type II landmarks of ventral view of the head, four type II landmarks of the pronotum and eight type I landmarks of the wings were defined and collected using TPS dig 2.17 [35] for each individual (Fig. 2b-d). Ventral view of the head was used to minimize error digitalization because it is more planar than dorsal view. For the head and pronotum, the average of the landmarks on both sides (four landmarks) was used to reduce intraindividual variation and minimize digitization errors [36].

Shape variables were obtained through the generalized Procrustes analysis superimposition algorithm and the subsequent projection of the Procrustes residuals into a Euclidean space [37]. Both non-uniform and uniform components [38] were used as shape variables. These two components describe the differences in shape as deviations from an average configuration of landmarks. The uniform component describes global variation such as stretching and compression, and the non-uniform component corresponds to local variation [39]. The 
isometric estimator centroid size (CS) derived from the landmark based analysis was used as a measure of overall size [40].

\section{Statistical analysis}

We analyzed linear and geometric variables of the three modules, i.e. head, pronotum and wings, separately. Species were grouped in two different ways for the analyses. One clustering considered interspecific comparisons, i.e. T. garciabesi, T. guasayana, T. patagonica and T. sordida from Argentina, Brazil and Bolivia as a single species. The other group included comparisons among closely related taxa, i.e. T. garciabesi, T. sordida Arg and T. sordida Brazil and Bolivia as three different taxa (Table 1). Brazilian and Bolivian T. sordida populations were grouped because a phylogenetic analysis showed that they belong to a unique clade separated from the Argentine population (see figure 3 in [7]).
We performed Discriminant Function Analysis (DFA) per module for linear and shape measurements for both groups (i.e. interspecific comparisons and comparisons among closely related taxa, see above). For shape measurements, Mahalanobis distances between pairs of species were calculated and their significance was evaluated using a non-parametric test based on permutations (1000 runs). We represented the Mahalanobis distances between pairs of species or closely related taxa in neighbor joining (NJ) trees. The percentage of phenotypic similarity between pairs of species was calculated using the cross-check test of discriminant analysis $[40,41]$.

The relationship between CS and shape discrimination among groups (allometry) was estimated using a multivariate regression between the Procrustes coordinates (dependent variables) and the CS (independent variable). This analysis was performed for each module and for both groups. These regressions showed a significant
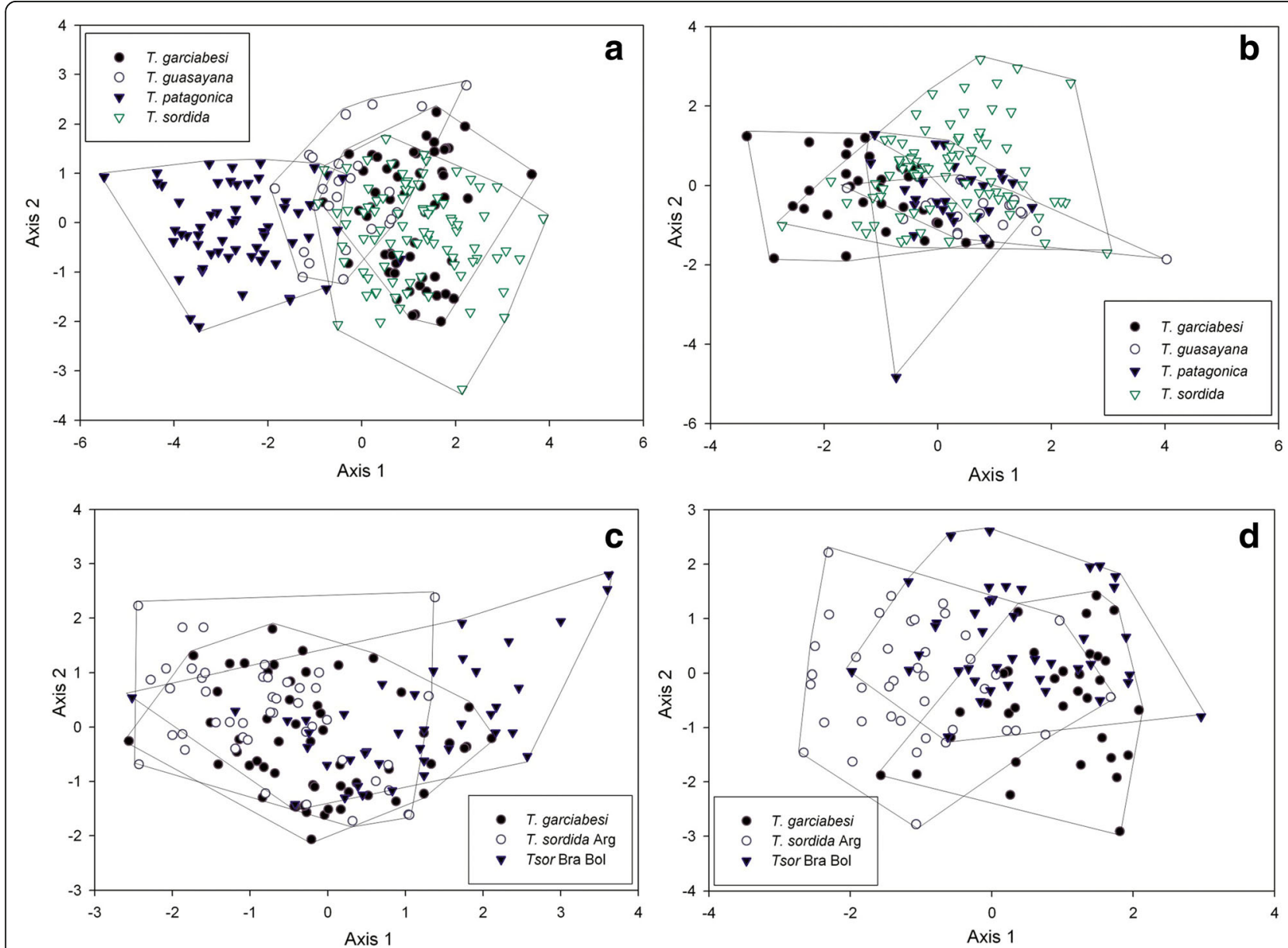

Fig. 3 Factorial maps in the plane of the two first axes of discriminant function analysis for linear measurements of the head and pronotum in populations of Triatoma garciabesi, T. guasayana, T. sordida and T. patagonica. For easy visualization, the lines connect the most external individuals of each population. Centroids are represented with the same symbol that identifies each species. a Head measurements of the four species. b Pronotum measurements of the four species. c Head measurements of T. garciabesi, T. sordida Argentina and T. sordida Brazil and Bolivia. d Pronotum measurements of T. garciabesi, T. sordida Argentina and T. sordida Brazil and Bolivia 
association $(P<0.01)$ in all groups of comparisons except for wings from $T$. garciabesi, $T$. sordida Arg and T. sordida Brazil and Bolivia. Since the allometric effect was small for wings $(1.8 \%)$ and heads $(2.8 \%)$, the DFA analyses were performed with the original Procrustes coordinate values. For the pronotum, the regression confirmed a strong allometric effect, accounting for 18.30\% (81.70\% for the non-allometric component) of the total shape variance for the comparison of the four species and $19.23 \%$ (80.77\% for the non-allometric component) for the comparison of T. garciabesi, T. sordida Arg and $T$. sordida Brazil and Bolivia. For these cases, the residual values from the multivariate regression analysis were used to investigate shape variation independent of size, i.e. the non-allometric component [42].

For comparing overall wing size among species, the CS was used in an ANOVA with a post-hoc Tukey's tests. The software InfoStat [43] was used for linear analysis and the software MorphoJ [44], the CLIC 98 package (http://mome-clic.com) and JMP v. 6.0.0 (SAS Institute Inc., 2005) for shape variables.

\section{Results}

\section{Linear morphometric analysis}

\section{Interspecific comparisons}

DFA performed for head linear measurements of the four species showed that the first two discriminant factors explained 96.89 and $2.70 \%$ of the total variation, respectively. Of the five linear measurements included in the DFA, head width was the one that best discriminated between species for the first two axes. The factorial distribution map of each individual in the space of the first DFA axes showed that T. patagonica was the only highly differentiated species $(86 \%$ of the correctly assigned individuals) (Fig. 3a, Table 2). The other three species overlapped in their distribution in the

Table 2 Reclassification of Triatoma garciabesi (T. gar), T. guasayana (T. gua), T. patagonica (T. pat) and T. sordida (T. sor) performed for linear variables of the head and pronotum. The number and percentage of assigned individuals derived from discriminant function analyses are presented

\begin{tabular}{lllllll}
\hline Species & $\begin{array}{l}\text { No. of } \\
\text { individuals }\end{array}$ & $\begin{array}{l}\text { T. gar } \\
n(\%)\end{array}$ & $\begin{array}{l}\text { T. sor } \\
n(\%)\end{array}$ & $\begin{array}{l}\text { T. gua } \\
n(\%)\end{array}$ & $\begin{array}{l}\text { T. pat } \\
n(\%)\end{array}$ & Module \\
\hline T. gar & 56 & $21(38)$ & $23(41)$ & $12(21)$ & $0(0)$ & Head \\
& 33 & $21(64)$ & $6(18)$ & $2(6)$ & $4(12)$ & Pronotum \\
T. sor & 88 & $29(33)$ & $39(44)$ & $19(22)$ & $1(1)$ & Head \\
& 83 & $15(18)$ & $40(48)$ & $18(22)$ & $10(12)$ & Pronotum \\
T. gua & 25 & $3(12)$ & $4(16)$ & $14(56)$ & $4(16)$ & Head \\
& 19 & $1(5)$ & $1(5)$ & $13(68)$ & $4(21)$ & Pronotum \\
T. pat & 57 & $0(0)$ & $1(2)$ & $7(12)$ & $49(86)$ & Head \\
& 24 & $4(17)$ & $7(29)$ & $6(25)$ & $7(29)$ & Pronotum \\
\hline
\end{tabular}

morphometric space and had low percentages of assignment (38-56\%), with $41 \%$ of $T$. garciabesi individuals being assigned to $T$. sordida and $33 \%$ of $T$. sordida individuals being assigned to $T$. garciabesi. Triatoma guasayana had 12 to $16 \%$ of individuals assigned to the other three species (Table 2).

The first discriminant factor of the DFA performed for pronotum measurements explained $70.29 \%$ of total variation, with pronotum length being the variable that best discriminated species along this axis. The second axis, explained mostly by pronotum area, explained $28.79 \%$ of the total variation. The factorial map showed low differentiation between species (Fig. 3b), with T. guasayana showing the lowest misclassification error followed by $T$. garciabesi (32 and 36\%, respectively, Table 2). About half of the $T$. sordida individuals (52\%) were incorrectly assigned, but only $18 \%$ were attributed to $T$. garciabesi. Unlike DFA results for head, the results for pronotum yielded the highest percentage of misassigned T. patagonica individuals (71\%).

\section{Comparisons among closely related taxa}

The first two axes of the DFA for head measurements explained the whole variation (94.62 and 5.38\% for first and second axes, respectively). Length of preocular region discriminated best these entities. The factorial map showed low discrimination between groups in this space (Fig. 3c), with T. garciabesi exhibiting $45 \%$ of the individuals assigned to T. sordida Arg, as well as the highest misclassification error $(62.50 \%$, Table 3$)$. Triatoma sordida Brazil and Bolivia showed $39 \%$ of misclassified individuals, with $37 \%$ being assigned to $T$. garciabesi. For T. sordida Arg. $26 \%$ of the individuals were assigned to $T$. garciabesi and only $6 \%$ to $T$. sordida Brazil and Bolivia. For pronotum measurements, the first two DFA axes explained the whole variation (75.30 and $24.70 \%$ for first and second axes, respectively) with pronotum area being the variable that better

Table 3 Reclassification of the closely related taxa T. sordida from Argentina (T. sor Arg), T. sordida from Brazil and Bolivia (T. sor BB) and T. garciabesi (T. gar) performed for linear variables of the head and pronotum. The number and percentage of assigned individuals derived from discriminant function analyses are presented

\begin{tabular}{llllll}
\hline Species & $\begin{array}{l}\text { No. of } \\
\text { individuals }\end{array}$ & $\begin{array}{l}\text { T. gar } \\
n(\%)\end{array}$ & $\begin{array}{l}\text { T. sor Arg } \\
n(\%)\end{array}$ & $\begin{array}{l}\text { T. sor BB } \\
n(\%)\end{array}$ & Module \\
\hline T. gar & 56 & $21(38)$ & $25(45)$ & $10(18)$ & Head \\
& 33 & $21(64)$ & $4(12)$ & $8(24)$ & Pronotum \\
T. sor Arg & 47 & $12(26)$ & $32(68)$ & $3(6)$ & Head \\
& 42 & $5(12)$ & $31(74)$ & $6(14)$ & Pronotum \\
T. sor BB & 41 & $15(37)$ & $1(2)$ & $25(61)$ & Head \\
& 41 & $10(24)$ & $11(27)$ & $20(49)$ & Pronotum \\
\hline
\end{tabular}


discriminated groups. The factorial map did not show a good differentiation between groups (Fig. 3d). However, misclassification error improved for T. sordida Arg (26\%) and T. garciabesi (36\%) in comparison with head DFA results (Table 3). For T. sordida Brazil and Bolivia misclassification error was $51 \%$.

\section{Geometric morphometric analysis \\ Interspecific comparison}

The first two axes of the DFA for head shape variation explained 96.92 and $1.96 \%$, respectively. Mahalanobis distances across the four species showed significant differences between all pairs of species except for $T$. sordida and T. garciabesi (Table 4). When Mahalanobis distances were used to build a NJ tree, these two species appeared as the most similar, followed by $T$. guasayana (which was equally separated from all the other species) and $T$. patagonica which was the most distant species from $T$. sordida and T. garciabesi (Fig. 4a). In addition, $T$. sordida and $T$. garciabesi showed the lowest percentage of correctly assigned individuals derived from the DFA analysis $(63 \%$ for $T$. sordida and $53 \%$ for $T$. garciabesi, Table 5) and appeared completely overlapped in the factorial map (Additional file 1: Figure S1). No individual of these two species was assigned to T. patagonica nor was any individual of $T$. patagonica assigned to T. sordida or $T$. garciabesi (Table 5).

The first two DFA axes performed for the nonallometric component of pronotum shape variation explained $99.74 \%$ of total variation $(87.65 \%$ for axis 1 and $12.07 \%$ for axis 2). Mahalanobis distances showed significant differences for all pairs of species except for the comparison between $T$. garciabesi and T. guasayana (Table 4, Fig 4b). The NJ tree differed from the tree obtained for head measures. The most similar species were T. garciabesi and T. guasayana and the most different species was $T$. sordida (Fig. 4b). The factorial map showed that species were partially overlapped in the space of the first two axes (Additional file 1: Figure S1), with $T$. garciabesi being the only species that showed the lowest percentage of correctly assigned individuals (25\%, Table 5, Fig. 4b). Triatoma sordida was the best classified species according to results for this structure (69\%).

Wing shape variation was explained by the first two DFA axes (64\% for axis 1 and 31\% for axis 2). Mahalanobis distances were significant between all pairs of species (Table 4). The NJ tree was similar to the NJ tree based on head measurements but T. guasayana was closer to $T$. patagonica (Fig. 4c). Wing shape exhibited the best percentages of assignment for all species, except for T. sordida (Table 5). The factorial map showed that the distribution in the space of the first two DFA axes of $T$. garciabesi overlapped that of the other three species $(29 \%$ of misclassified individuals), and $T$. patagonica was the species with the best discrimination (90\% of correctly classified individuals) (Table 5, Additional file 1: Figure S1).

Comparison of wing CS among the four species showed significant differences $\left(F_{(3,} 240\right)=9.83$, $P=0.0001)$. The post-hoc Tukey's tests revealed significant differences among $T$. sordida, $T$. guasayana and $T$. patagonica and between $T$. garciabesi and $T$. patagonica (all $P<0.05$ ).

\section{Comparisons among closely related taxa}

The first two DFA axes for head shape contained the whole variation (axis 1: $80.42 \%$; axis 2: 19.58\%). No differences were detected in Mahalanobis distances between $T$. sordida Arg and T. garciabesi (Table 4). These species formed the pair most closely clustered in the NJ (Fig. 5a). Percentages of correctly assigned individuals were low for T sordida Arg, with only $41 \%$ of individuals being correctly assigned (Table 6).

The first two axes of the DFA performed for the nonallometric component of pronotum shape contained

Table 4 Mahalanobis distances between pairs of species performed for shape variables of the head, pronotum and wings. Interspecific comparison: Triatoma garciabesi (T. gar), T. guasayana (T. gua), T. patagonica (T. pat) and T. sordida (T. sor). Comparison among closely related taxa: T. sordida from Argentina (T. sor Arg), T. sordida from Brazil and Bolivia (T. sor BB) and T. garciabesi (T. gar)

\begin{tabular}{|c|c|c|c|c|}
\hline Group & Pairs of species & Head & Pronotum & Wing \\
\hline \multirow[t]{6}{*}{ T. gar, T. gua, T. pat, T. sor } & T. gar vs T. gua & $2.01^{* * *}$ & 0.64 & $2.71^{* * *}$ \\
\hline & T. gar vs T. pat & $3.84^{* * *}$ & $1.11^{* *}$ & $3.07^{* * *}$ \\
\hline & T. gar vs T. sor & 0.58 & $1.49^{* * *}$ & $1.22^{* * *}$ \\
\hline & T. gua vs T. pat & $2.07^{* * *}$ & $1.38^{*}$ & $2.24^{* * *}$ \\
\hline & T. gua vs T. sor & $2.30^{* * *}$ & $2.00^{* * *}$ & $2.78^{* * *}$ \\
\hline & T. pat vs T. sor & $4.11^{* * *}$ & $1.62^{* * *}$ & $3.45^{* * *}$ \\
\hline \multirow[t]{3}{*}{ T. gar, T. sor Arg, T. sor BB } & T. sor Arg vs T. sor BB & $1.21^{* * *}$ & $1.18^{* * *}$ & $2.18^{* * *}$ \\
\hline & T. sor Arg vs T. gar & 0.61 & $1.38^{* * *}$ & $1.27^{* *}$ \\
\hline & T. sor BB vs T. gar & $1.18^{* * *}$ & $1.88^{* * *}$ & $1.87^{* * *}$ \\
\hline
\end{tabular}




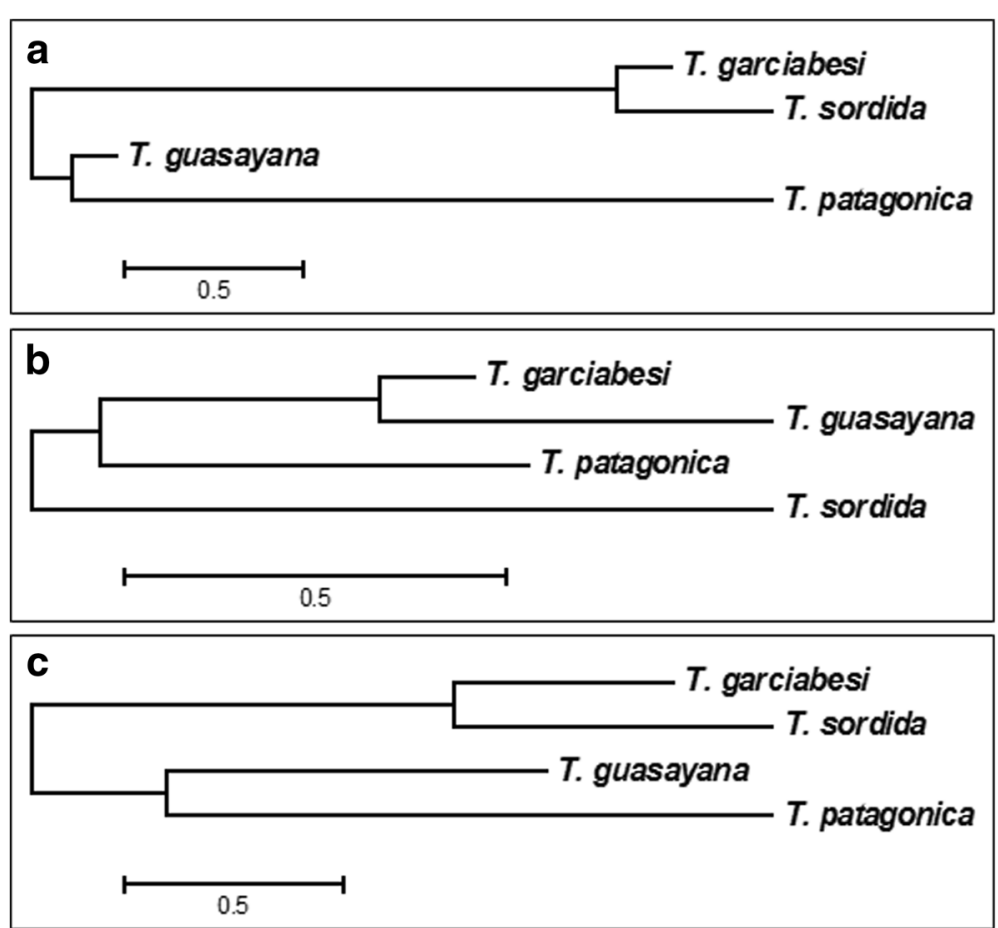

Fig. 4 Neighbor-joining trees derived from Mahalanobis distances of shape measurements for the head, pronotum and wings in populations of T. garciabesi, T. guasayana, T. sordida and T. patagonica. a Head measurements. b Pronotum measurements. c Wing measurements

$100 \%$ of the variation (axis 1: $76.35 \%$; axis 2: $23.75 \%$ ). Mahalanobis distances between the three groups were significant, with $T$. garciabesi being the most divergent species in the NJ tree (Fig. 5b). The factorial map showed that $T$. sordida Arg overlapped in the space of

Table 5 Reclassification of Triatoma garciabesi (T. gar), T. guasayana (T. gua), T. patagonica (T. pat) and T. sordida (T. sor) performed for shape variables of the head, pronotum and wings. The number and percentage of correctly assigned individuals derived from discriminant function analyses are presented

\begin{tabular}{lllllll}
\hline Species & $\begin{array}{l}\text { No. of } \\
\text { individuals }\end{array}$ & $\begin{array}{l}\text { T. gar } \\
n(\%)\end{array}$ & $\begin{array}{l}\text { T. sor } \\
n(\%)\end{array}$ & $\begin{array}{l}\text { T. gua } \\
n(\%)\end{array}$ & $\begin{array}{l}\text { T. pat } \\
n(\%)\end{array}$ & Module \\
\hline T. gar & 56 & $30(53)$ & $19(34)$ & $7(13)$ & $0(0)$ & Head \\
& 32 & $8(25)$ & $5(16)$ & $9(28)$ & $10(31)$ & Pronotum \\
& 55 & $39(71)$ & $12(22)$ & $3(5)$ & $1(2)$ & Wing \\
T. sor & 82 & $25(31)$ & $52(63)$ & $5(6)$ & $0(0)$ & Head \\
& 73 & $12(16)$ & $50(69)$ & $1(1)$ & $10(14)$ & Pronotum \\
& 91 & $26(29)$ & $56(62)$ & $6(6)$ & $3(3)$ & Wing \\
T. gua & 26 & $1(4)$ & $3(12)$ & $17(65)$ & $5(19)$ & Head \\
& 19 & $2(11)$ & $4(21)$ & $12(63)$ & $1(5)$ & Pronotum \\
& 39 & $1(3)$ & $2(5)$ & $27(69)$ & $9(23)$ & Wing \\
T. pat & 50 & $0(0)$ & $0(0)$ & $7(14)$ & $43(86)$ & Head \\
& 26 & $7(27)$ & $1(4)$ & $2(8)$ & $16(61)$ & Pronotum \\
& 50 & $2(4)$ & $0(0)$ & $3(6)$ & $45(90)$ & Wing \\
\hline
\end{tabular}

the first two DFA axes with the other two groups $(46 \%$ were correctly assigned) (Additional file 2: Figure S2). Triatoma sordida Brazil and Bolivia and T. garciabesi both showed $66 \%$ of correctly assigned individuals (Table 6).

For wing shape, the first two axes explained 78 and $22 \%$ of the total variation, respectively. All pairs of species showed significant differences for Mahalanobis distances (Table 4), and the NJ tree was similar to the one based on head measures (Fig. 5c). The factorial map showed an overlap in the space of the first two axes among the three groups (Additional file 2: Figure S2). The correct assignment of individuals was $67 \%$ for $T$. garciabesi, $80 \%$ for $T$. sordida Brazil and Bolivia, and $63 \%$ for $T$. sordida Arg (Table 6). ANOVA test for wing CS revealed no significant differences among groups $\left(F_{(2,144)}=0.86, P=0.416\right)$.

\section{Discussion}

Interspecific comparison

Our results showed significant morphological differences among the species of the Sordida subcomplex for the head, pronotum and wing size and shape. We made an important sampling effort in order to cover the morphological variability across almost the entire distribution area of the four species. Moreover, we included the pronotum, a morphological trait that still 


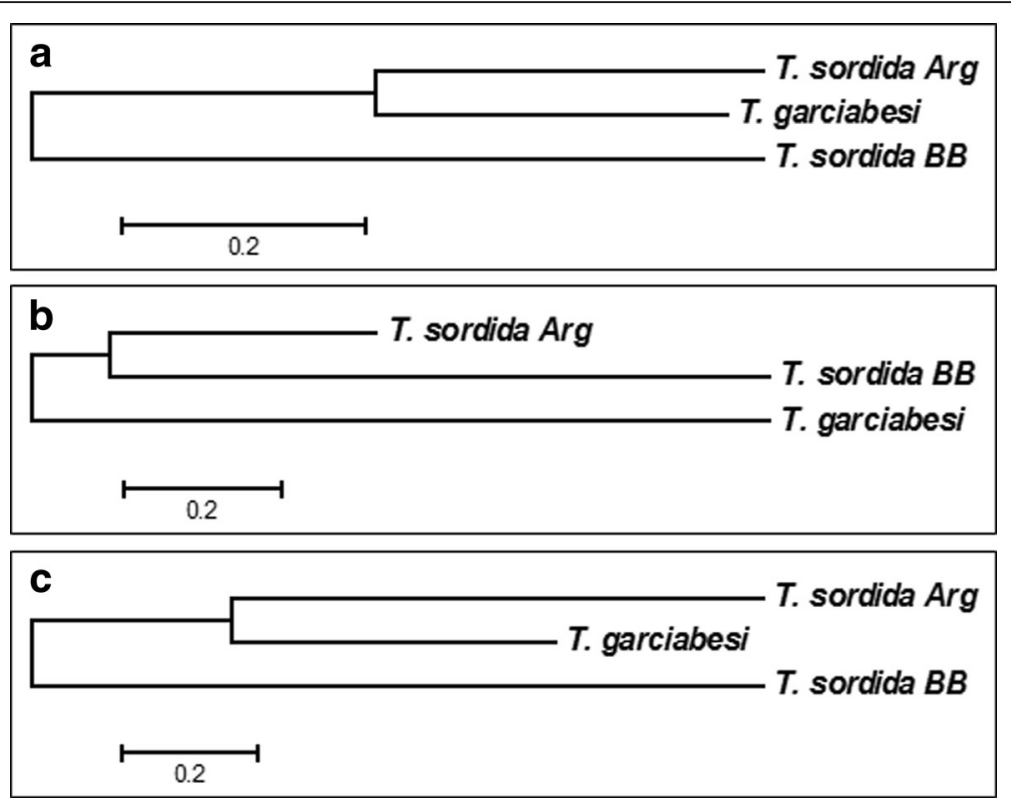

Fig. 5 Neighbor-joining trees derived from Mahalanobis distances of shape measurements for the head, pronotum and wings in populations of $T$. garciabesi, T. sordida from Argentina and T. sordida from Brazil and Bolivia. a Head measurements. b Pronotum measurements. c Wing measurements

remains mostly unexplored in studies of morphological variability in the Triatominae.

Wing shape was the only trait that differed in all pairwise comparisons and displayed the lowest classification error in relation to the other two measured structures in all species except for T. sordida. Triatoma patagonica exhibited the highest percentage of correctly assigned individuals. This result is in agreement with a previous study where wing shape, rather than head shape, was the character that better discriminated populations of $T$. sordida and T. garciabesi [21]. Wing shape has also

Table 6 Reclassification of the closely related taxa T. sordida from Argentina (T. sor Arg), T. sordida from Brazil and Bolivia (T. sor BB) and T. garciabesi (T. gar) performed for shape variables of the head, pronotum and wings. The number and percentage of correctly assigned individuals derived from discriminant function analyses are presented

\begin{tabular}{llllll}
\hline Species & $\begin{array}{l}\text { No. of } \\
\text { individuals }\end{array}$ & $\begin{array}{l}\text { T. gar } \\
n(\%)\end{array}$ & $\begin{array}{l}\text { T. sor Arg } \\
n(\%)\end{array}$ & $\begin{array}{l}\text { T. sor BB } \\
n(\%)\end{array}$ & Module \\
\hline T. gar & 56 & $32(57)$ & $15(27)$ & $9(16)$ & Head \\
& 32 & $21(66)$ & $9(28)$ & $2(6)$ & Pronotum \\
& 54 & $36(67)$ & $13(24)$ & $5(9)$ & Wing \\
T. sor Arg & 44 & $15(34)$ & $18(41)$ & $11(25)$ & Head \\
& 41 & $10(24)$ & $19(46)$ & $12(29)$ & Pronotum \\
& 46 & $11(24)$ & $29(63)$ & $6(13)$ & Wing \\
T. sor BB & 38 & $5(13)$ & $5(13)$ & $28(74)$ & Head \\
& 32 & $5(16)$ & $6(19)$ & $21(66)$ & Pronotum \\
& 46 & $6(13)$ & $3(7)$ & $37(80)$ & Wing \\
\hline
\end{tabular}

shown to be less conservative than head shape and presented higher values of Mahalanobis distances within the Triatoma brasiliensis species complex [28]. Results of linear and morphogeometric measurements of the head were consistent with those of the wings, with $T$. patagonica having the highest percentage of correctly assigned individuals. Triatoma sordida and T. garciabesi did not present differences in head shape (Mahalanobis distances were not significantly different) and had a high percentage of incorrectly assigned individuals between them (31 and $34 \%$ of individuals were assigned to the other species). Linear and shape pronotum measurements did not show a good assignation percentage for any species. However, pronotum linear measurements improved the percentage of correctly assigned individuals for $T$. sordida, $T$. garciabesi and $T$. guasayana compared to head linear measurements, suggesting pronotum size differences. Pronotum shape was the module that best classified T. sordida, but had the highest misclassification error for the other three species. NJ tree topologies showed consistently for wings and head, that $T$. sordida and $T$. garciabesi were more similar to each other than to the other two species of the subcomplex.

Our study showed that T. patagonica was the best differentiated species of the subcomplex for head and wing shape, and T. guasayana for pronotum linear measurements. In another study, 17 metric variables of different parts of the body were compared among T. sordida, $T$. guasayana and T. patagonica (T. garciabesi was considered a synonym of $T$. sordida). Triatoma guasayana and $T$. sordida were completely separated by a discriminant 
function based on two head measurements, anteocular and second rostral lengths, whereas the three species were discriminated using 14 linear measurements for head, pronotum and abdomen, with a small overlap between T. guasayana and T. patagonica [14]. Genetic studies based on isoenzymes, chromosome C-heterocromatine banding and mitochondrial sequences have also shown differences between $T$. patagonica, $T$. guasayana and the other species of the Sordida subcomplex [19, 45, 46]. Triatoma patagonica is also easily distinguished from the other three species of the subcomplex by its completely dark legs in contrast to the light-colored legs of the other three species [18]. Molecular and cytogenetic analyses and the composition of cuticular hydrocarbons suggest that the taxonomy of the subcomplex should be revised [46-49]. Recent phylogenetic analyses and the chromosomal position of ribosomal genes have placed $T$. patagonica and T. guasayana within the Rubrovaria subcomplex and have suggested the reorganization of several subcomplexes within the genus Triatoma, including the Sordida subcomplex. In this new proposal, the Sordida subcomplex is composed of six species: $T$. sordida, T. garciabesi, T. jurbergi, T. matogrossensis, T. vandae and $T$. sordida from Argentina, the latter being considered a new species [46].

The present results showed that, despite significant morphological differences in wing shape and pronotum linear measures and shape between T. sordida and $T$. garciabesi, these species were not well discriminated based on morphological traits. One possibility to explain this result is that individuals from some particular populations were incorrectly identified; another possibility is that morphological characters of some populations differ from the average values for the species due to local adaptation or genetic drift acting in small populations. However, the identity of the misclassified $T$. garciabesi and $T$. sordida individuals by DFA for the different modules was revised, showing that all of them belonged to different populations and the particular identity of each misclassified individual (i.e. individual code number) was not always the same (data not shown). These results suggest that these two species could live in sympatry more often than suspected, even in the same site, with putative hybrids that would hinder morphological identification and morphological delimitation of species [21]. One possibility, suggested to occur in this subfamily (e.g. $[1,50]$ ), is that these two species have speciated very recently and still remain very similar morphologically, with a high degree of phenotypic plasticity across the species distribution area or morphological convergence [50]. Another possibility is that natural hybrids live in sympatry with their parents. This process has been reported to occur in T. sordida specimens from La Paz, Bolivia [7].
The taxonomic validity of $T$. garciabesi has been supported by the morphology of the male genitalia, isoenzymatic, molecular, morphometric and cytogenetic traits [17, 19-21, 51]; however, cross-breeding experiments between $T$. garciabesi and $T$. sordida still have not been described and could provide additional evidence for their species status. Also, the search of natural hybrids between $T$. sordida and $T$. garciabesi may shed light on this matter and help understand the possible stage of the process of speciation for these two entities and if there are reproductive isolation mechanisms operating in natural populations.

\section{Comparison among closely related taxa}

The proposed species T. sordida Arg differed from $T$. sordida Brazil and Bolivia in all shape traits, but showed the lowest percentage of correctly assigned individuals for shape measurements of the three modules. However, it exhibited the best discrimination for linear measurements of head and pronotum. Triatoma sordida from Brazil and Bolivia exhibited, the highest correctly assigned individuals for the three structures, suggesting a small range of intraspecific variation and a better delimitation than T. sordida Arg. Triatoma sordida from Brazil and Bolivia was the best discriminated for all shape measurements, followed by $T$. garciabesi. In addition, individuals from both $T$. sordida groups were more often confused with $T$. garciabesi than with each other; head shape from T. sordida Arg and T. garciabesi were not differentiated. NJ trees for wing and head shape illustrated this pattern, with $T$. sordida Arg and T. garciabesi being more similar than T. sordida from Brazil and Bolivia.

Our results for $T$. sordida Arg and $T$. sordida from Brazil and Bolivia suggest that the proposed cryptic speciation of $T$. sordida Arg is supported not only by chromosome patterns but also by morphological differentiation, since these two entities seem to be delimited by shape morphological traits. Moreover, body size and the pattern of connexivum variation seem to be different (Fig. 2a), although these characters may vary across populations as well as in other species of the Triatominae [52]. In another morphogeometric study of two Brazilian and one Argentine population of T. sordida and one population of $T$. garciabesi, the specimens of $T$. garciabesi and Brazilian T. sordida were well separated using head and wing shape whereas the Argentine population of $T$. sordida overlapped for wing and head shape with Brazilian T. sordida and with T. garciabesi [21].

Cryptic speciation in $T$. sordida was first reported for Bolivian populations, where two reproductively isolated cryptic species were living in sympatry in the Bolivian Chaco [20]. Molecular and cytogenetic studies suggest differences in $T$. sordida from Argentina compared with 
T. sordida in the remaining distribution area $[7,19]$. Moreover, T. sordida cuticular hydrocarbon composition exhibits a heterogeneous pattern, suggesting that it should not be considered a single species [48]. Nevertheless, molecular divergence between $T$. sordida from Argentina and T. sordida from Brazil was only 5.3\% [7], a similar value to that distinguishing subspecies of Triatoma sanguisuga (Le Conte, 1855) [53] and distant populations of $T$. patagonica [52].

For T. sordida from Argentina and T. garciabesi, the patterns of cuticular hydrocarbons of both species share some similarities [48]. Molecular divergence between T. sordida from Argentina and T. garciabesi based on mitochondrial DNA was $7 \%$, a similar value to that reported for species of the Brasiliensis subcomplex [7, 30]. Ecological niche modeling revealed clear differences between $T$. garciabesi and T. sordida from Argentina and Brazil, with T. garciabesi occupying colder and drier areas than T. sordida [21]. A low differentiation was achieved between $T$. sordida populations from the wet and dry regions of Argentina (those of the dry region were then described as T. garciabesi) [19]. The ecological niche occupied by these two species is not necessarily a criterion to delimit closely related sibling species, since, for example $T$. brasiliensis or $T$. dimidiata complexes occupied different ecological niches across their distribution areas $[54,55]$.

\section{Conclusions}

To our knowledge, this is the first morphometric study of the species of the Sordida subcomplex that covers almost the entire distribution area of the four species and that includes morphometric traits of the three modules, head, pronotum and wing. Our results suggest that wing shape would be a reasonably good phenotypic marker, since it distinguished the four species traditionally included in the Sordida subcomplex, including the putative new species $T$. sordida from Argentina. Triatoma sordida Arg, differed in all measured shape traits from T. sordida Brazil and Bolivia; however, additional studies integrating cytogenetic, phenotypic and molecular markers, as well as crossbreeding experiments are needed to confirm the validity of this putative new species.

\section{Additional files}

Additional file 1: Figure S1. Factorial maps in the plane of the two first axes of discriminant function analysis for shape measurements of the head, pronotum and wings in populations of T. garciabesi, T. guasayana, T. sordida and T. patagonica. For easy visualization, the lines connect the most external individuals of each population. Centroids were represented with the same symbol that identifies each species. a Head. b Pronotum. c Wings. (TIFF $42083 \mathrm{~kb}$ )

Additional file 2: Figure S2. Factorial maps in the plane of the two first axes of the discriminant function analysis for shape measurements of the head, pronotum and wings in populations of T. garciabesi, T. sordida from Argentina and T. sordida from Brazil and Bolivia. For easy visualization, the lines connect the most external individuals of each population. Centroids were represented with the same symbol that identifies each taxa. a Head. b Pronotum. c Wings. (TIFF 43228 kb)

\section{Acknowledgements}

We thank G. Leonhard and R. Stariolo (Centro de Referencia de Vectores (CeReVe), Ministerio de Salud de la Nación, Argentina), and E. B. Oscherov, A. Gonzalez and R. Cardozo for providing biological materials used in this study. R. Botero and E. Lucero participated in field work in the Reserva Telteca. A. Díaz and A. Perez Gonzalez for help with triatominae pictures. Y. Provecho made useful statistical suggestions. We also would like to thanks the two anonymous reviewers. JN, RP, MLH, LA and ALCF are members of the CONICET Researcher's Career. PL has a doctoral scholarship from CONICET.

\section{Funding}

This study was supported by awards from Agencia Nacional de Promoción Científica y Tecnológica (PICT 2013-1670, PICT 2014-1952, PICT 2013-2538 and PICT-PRH 2014-3746). The funding sources had no role in study design, data collection and analysis, decision to publish, or preparation of the manuscript.

\section{Availability of data and materials}

The datasets supporting the conclusions of this article are included within the article and its additional files. Raw data are available from the corresponding author on reasonable request.

\section{Authors' contributions}

Conceived and designed the experiments: JN, RVP and ALCF. Collected the insects: JN, MLH, CML, LA, PL, CSR and ALCF. Analyzed the data: JN, RVP, MLH, LA and ALCF. Wrote the manuscript: JN, RVP and ALCF. All authors read and approved the final manuscript.

Ethics approval and consent to participate

Not applicable.

\section{Consent for publication}

Not applicable.

\section{Competing interests}

The authors declare that they have no competing interests.

\section{Publisher's Note}

Springer Nature remains neutral with regard to jurisdictional claims in published maps and institutional affiliations.

\section{Author details}

${ }^{1}$ Facultad de Ciencias Exactas y Naturales, Departamento de Ecología, Genética y Evolución/Laboratorio de Eco-Epidemiología, Universidad de Buenos Aires, Ciudad Autónoma de Buenos Aires, Buenos Aires, Argentina. ${ }^{2}$ CONICET - Universidad de Buenos Aires, Instituto de Ecología, Genética y Evolución de Buenos Aires (IEGEBA), Ciudad Autónoma de Buenos Aires, Buenos Aires, Argentina. ${ }^{3}$ Laboratório Interdisciplinar de Vigilância Entomológica em Diptera e Hemiptera- Instituto Oswaldo Cruz, Avenida Brasil, 4365, Manguinhos, Rio de Janeiro 21040-900, Brazil. ${ }^{4}$ Centro Regional de Investigaciones Científicas y de Transferencia Tecnológica de La Rioja (CRILAR-CONICET), Entre Ríos y Mendoza s/n, 5301 La Rioja, Argentina. ${ }^{5}$ Centro de Referencia de Vectores, Ministerio de Salud de la Nación, Hospital Colonia, Pabellón Rawson calle s/n, X5164 Santa María de Punilla, Córdoba, Argentina. ${ }^{6}$ Intituto de Investigaciones Biológicas y Tecnológicas, CONICET, FCEFyN, UNC, Avenida Vélez Sarsfield 299, X5000JJC Córdoba, Argentina.

Received: 4 April 2017 Accepted: 29 August 2017

Published online: 06 September 2017

\section{References}

1. Justi SA, Galvão C. The evolutionary origin of diversity in Chagas disease vectors. Trends Parasitol. 2017;33:42-52.

2. Galvão C, Justi SA. An overview on the ecology of Triatominae (Hemiptera: Reduviidae). Acta Trop. 2015;151:116-25. 
3. Bar ME, Oscherov EB, Pieri Damborsky M, Borda M. Epidemiología de la tripanosomiasis americana en el Norte de Corrientes. Medicina. 2010;70:133-8.

4. Gonzalez-Britez NE, Carrasco HJ, Martínez Purroy CE, Feliciangeli MD, Maldonado M, López E, et al. Genetic and morphometric variability of Triatoma sordida (Hemiptera: Reduviidae) from the eastern and western regions of Paraguay. Front Public Health. 2014;2:149.

5. Rossi JCN, Duarte EC, Gurgel-Gonçalves R. Factors associated with the occurrence of Triatoma sordida (Hemiptera: Reduviidae) in rural localities of central-West Brazil. Mem Inst Oswaldo Cruz. 2015;110:192-200.

6. Silistino-Souza R, Alevi KCC, Castro NFC, Freitas MN, Papa MD, Scandar SAS, et al. Entoepidemiology of Chagas disease in northwest São Paulo and cytogenetic analysis of its main vector, Triatoma sordida (Hemiptera: Triatominae). Gen Mol Res. 2013;12:5810-9.

7. Panzera F, Pita S, Nattero J, Panzera Y, Galvão C, Chavez T, et al. Cryptic speciation in the Triatoma sordida subcomplex (Hemiptera, Reduviidae) revealed by chromosomal markers. Parasit Vectors. 2015;8:495

8. Abrahan L, Gorla D, Catalá S. Active dispersal of Triatoma infestans and other triatomines in the Argentinean arid Chaco before and after vector control interventions. J Vector Ecol. 2016;41:90-6.

9. Cavallo MJ, Amelotti I, Gorla DE. Invasion of rural houses by wild Triatominae in the arid Chaco. J Vector Ecol. 2016;41:97-102.

10. Canale DM, Cecere MC, Chuit R, Gürtler RE. Peridomestic distribution of Triatoma garciabesi and Triatoma guasayana in north-west Argentina. Med Vet Entomol. 2000;14:383-90.

11. Ferrero AA, Visciarelli EC, Torno O, Costamagna SR. Presencia de Triatoma patagonica en viviendas humanas en la ciudad de Río Colorado, Provincia de Río Negro. Rev Soc Entomol Argent. 1999;58:79-84.

12. Giraldez E, López Ureta MP, Nepote M. Colonización domiciliaria por Triatoma patagonica en el departamento San Cristóbal, provincia de Santa Fe. Rev Méd Rosario. 2009;75:38.

13. de la Fuente AL C, Lencina P, Spillmann C, Gürtler RE. Mechanical versus motorized vehicle-mounted sprayers: performance evaluation of a new method for Chagas disease vector control. Cad Saúde Pública. 2017;33:1-11.

14. Gorla DE, Jurberg J, Catalá SS, Schofield CJ. Systematics of Triatoma sordida, T. guasayana and T. patagonica (Hemiptera, Reduviidae). Mem Inst Oswaldo Cruz. 1993;88:379-85.

15. Carcavallo RU, Cichero JA, Martínez A, Prosen AF, Ronderos R. Una nueva especie del género Triatoma Laporte (Hemiptera, Reduviidae, Triatominae). Segundas J Entomol Arg. 1967;2:43-8.

16. Lent $H$, Wygodzinsky P. A revision of the Triatominae (Hemiptera, Reduviidae) and their significance as vectors of Chagas disease. Bull Am Mus Nat His. 1979;163:1-520.

17. Jurberg J, Galvão C, Lent H, Monteiro F, Macedo Lopes C, Panzera F, et al. Revalidação de Triatoma garciabesi Carcavallo, Cichero, Martínez, Prosen \& Ronderos, 1967 (Hemiptera-Reduviidae). Entomol Vectores. 1998;5:107-22.

18. Carcavallo RU, Martínez A. Chapter 2. In: Carcavallo RU, Martínez A, editors. Enfermedad de Chagas y sus transmisores. entomoepidemiología de la República Argentina, Buenos Aires, Argentina: XXIII Comunicaciones Científicas de las Fuerzas Armadas; 1968. p. 23-103.

19. Panzera F, Hornos S, Pereira J, Cestau R, Canale D, Diotaiuti L, et al. Genetic variability and geographic differentiation among three species of triatomine bugs (Hemiptera-Reduviidae). Am J Trop Med Hyg. 1997;57:732-9.

20. Noireau F, Gutierrez T, Zegarra M, Flores R, Brenière F, Cardozo L, et al. Cryptic speciation in Triatoma sordida (Hemiptera: Reduviidae) from the Bolivian Chaco. Tropical Med Int Health. 1998;3:364-72.

21. Gurgel-Gonçalves R, Ferreira JBC, Rosa AF, Bar ME, Galvão C. Geometric morphometrics and ecological niche modelling for delimitation of nearsibling triatomine species. Med Vet Entomol. 2011;25:84-93.

22. Rodríguez Rodríguez J, Fuentes González O, Nodarse JF, Monzote Fidalgo L, Dujardin JP. Cambios morfométricos de Triatoma flavida Neiva, 1911 (Hemiptera: Triatominae) que ocurrieron cuando fueron llevados desde su hábitat selvático al laboratorio. Rev Inst Med Trop Sao Pablo. 2007:49:127-30.

23. Hernández ML, Abrahan LB, Dujardin JP, Gorla DE, Catalá SS. Phenotypic variability and population structure in peridomestic Triatoma infestans (Hemiptera, Reduviidae): influence of macro and micro habitat. Vector Borne Zoon Dis. 2011;11:503-13.

24. Dujardin JP. Modern morphometrics of medically important insects. Inc Genet Evol Infect Dis. 2011:473-501.

25. Monte Gonçalvez TC, Teves Neves SC, dos Santos Mallet JR. Carbajal de la Fuente AL, Macedo Lopez C. Triatoma jatai sp. nov. in the state of
Tocantins, Brazil (Hemiptera: Reduviidae: Triatominae). Mem Inst Oswaldo Cruz. 2013;108:429-37.

26. Vendrami DP, Takashi Obara M, Gurgel-Gonçalves R, Ceretti-Junior W, Toledo MM. Wing geometry of Triatoma sordida (Hemiptera: Reduviidae) populations from Brazil. Inf Gen Evol. 2017;49:17-20.

27. Dujardin JP, Beard B, Ryckman R. The relevance of wing geometry in entomological surveillance of Triatominae, vectors of Chagas disease. Inf Gen Evol. 2007;7:161-7.

28. Oliveira J, Marcer PL, Takiya DM, Mendonça VJ, Belintani T, Bargues MD, et al. Combined phylogenetic and morphometric information to delimit and unify the Triatoma brasiliensis species complex and the Brasiliensis subcomplex. Acta Trop. 2017;170:140-8.

29. Lehmann P, Ordoñez R, Ojeda-Baranda R, Mendez de Lira J, Hidalgo-Sosa L, Monroy C, et al. Morphometric analysis of Triatoma dimidiata populations (Reduviidae: Triatominae) from Mexico and Northern Guatemala. Mem Inst Oswaldo Cruz. 2005;100:477-86.

30. Monteiro FA, Donnelly MJ, Beard CB, Costa J. Nested clade and phylogeographic analyses of the Chagas disease vector Triatoma brasiliensis in Northeast Brazil. Mol Phylogen Evol. 2004:32:46-56.

31. Bargues MD, Klisiowicz DR, Gonzalez-Candelas F, Ramsey JM, Monroy C,

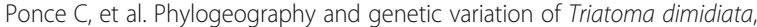
the main Chagas' disease vector in central America, and its position within the genus Triatoma. PLoS Negl Trop Dis. 2008;2:e233.

32. Almeida CE, Oliveira HL, Correia N, Dornak LL, Gumiel M, Neiva VL, et al. Dispersion capacity of Triatoma sherlocki, Triatoma juazeirensis and laboratory-bred hybrids. Acta Trop. 2012;122:72-9.

33. Hernández ML, Dujardin JP, Gorla DE, Catalá SS. Can body traits, other than wings, reflect the flight ability of Triatominae bugs? Rev Soc Bras Med Trop. 2015;48:682-91.

34. Wilcox CD, Dove SB, McDavid WD, Greer DB. UTHSCSA Image Tool Version 3.0. Texas: University of Texas Health Science Center; 2002.

35. Rohlf FJ. TPSDig 2.17. New York: Stony Brook University; 2013.

36. Hernández ML, Dujardin JP, Gorla DE, Catalá SS. Potential sources of Triatoma infestans reinfesting peridomiciles identified by morphological characterization in los Ilanos, La Rioja, Argentina. Mem Inst Oswaldo Cruz. 2013;108:91-7.

37. Rohlf FJ. Shape statistics: procrustes superimpositions and tangent spaces. J Classif. 1999:16:197-223.

38. Rohlf FJ. Morphometrics. Annu Rev Ecol Syst. 1990;21:299-316.

39. Zelditch ML, Swiderski DL, Sheets HD, Fink WL. Geometric morphometrics for biologists: a primer. New York and London: Elsevier Academic Press; 2004

40. Bookstein FL. Morphometric tools for landmark data. Cambridge: Cambridge University Press; 1991

41. Lachenbruch PA. An almost unbiased method of obtaining confidence intervals for the probability of misclassification in discriminant analysis. Biometrics. 1967:23:639-45.

42. Debat $\mathrm{V}$, Béagin $\mathrm{M}$, Legout $\mathrm{H}$, David JR. Allometric and nonallometric components of Drosophila wing shape respond differently to developmental temperature. Evolution. 2003;57:2773-84.

43. Di Rienzo JA, Casanoves F, Balzarini MG, González L, Tablada M, Robledo CW. InfoStat versión 2016. Grupo InfoStat. Córdoba: FCA, Universidad Nacional de Córdoba; 2016.

44. Klingenberg CP. MorphoJ: an integrated software package for geometric morphometrics. Mol Ecol Res. 2011;11:353-7.

45. Noireau F, Gutierrez T, Flores R, Brenière F, Bosseno MF, Wisnivesky-Colli C. Ecogenetics of Triatoma sordida and Triatoma guasayana (Hemiptera: Reduviidae) in the Bolivian Chaco. Mem Inst Oswaldo Cruz. 1999;94:451-7.

46. Pita S, Lorite P, Nattero J, Galvão C, Alevi KCC, Teves SC, et al. New arrangements on several species subcomplexes of Triatoma genus based on the chromosomal position of ribosomal genes (Hemiptera Triatominae). Inf Gen Evol. 2016:43:225-31.

47. Hypša V, Tietz DF, Zrzavý J, Rego ROM, Galvão C, Jurberg J. Phylogeny and biogeography of Triatominae (Hemiptera: Reduviidae): molecular evidence of a new world origin of the Asiatic clade. Mol Phylogenet Evol. 2002;23:447-57.

48. Calderón-Fernández GM, Juárez MP. The cuticular hydrocarbons of the Triatoma sordida species subcomplex (Hemiptera: Reduviidae). Mem Inst Oswaldo Cruz. 2013;108:778-84.

49. Gardim S, Almeida CE, Takiya DM, Oliveira J, Araújo RF, Cicarelli RMB, et al. Multiple mitochondrial genes of some sylvatic Brazilian Triatoma: non- 
monophyly of the $T$. brasiliensis subcomplex and the need for a generic revision in the Triatomini. Infect Genet Evol. 2014;23:74-9.

50. Dujardin J-P, Costa J, Bustamante D, Jaramillo N, Catalá S. Deciphering morphology in Triatominae: the evolutionary signals. Acta Trop. 2009;110:101-11.

51. Justi SA, Russo CAM, Mallet JRS, Obara MT, Galvão C. Molecular phylogeny of Triatomini (Hemiptera: Reduviidae: Triatominae). Parasit Vectors. 2014;7:149.

52. Nattero J, Pita S, Calleros L, Crocco L, Panzera Y, Rodríguez CS, et al. Morphological and genetic differentiation within the southernmost vector of Chagas disease: Triatoma patagonica (Hemiptera - Reduviidae). PLoS One. 2016;11:e0168853.

53. de la Rua N, Stevens L, Dorn PL. High genetic diversity in a single population of Triatoma sanguisuga (le Conte, 1855) inferred from two mitochondrial markers: cytochrome $b$ and 16S ribosomal DNA. Infect Genet Evol. 2011;11:671-7.

54. Costa J, Dornak LL, Almeida CE, Peterson AT. Distributional potential of the Triatoma brasiliensis species complex at present and under scenarios of future climate conditions. Parasit Vectors. 2014;7:238.

55. Dorn PL, Monroy C, Curtis A. Triatoma dimidiata (Latreille, 1811): a review of its diversity across its geographic range and the relationship among populations. Infect Genet Evol. 2007;7:343-52.

56. Carcavallo RU, Curto de Casas SI, Sherlock IA, Galíndez Girón I, Jurberg J, Galvão C, et al. Geographical distribution and alti-latitudinal dispesion. In: Carcavallo RU, Galíndez Girón I, Jurberg J, H Lent, editors. Atlas of Chagas disease vectors in the Americas. Vol. 3. Chapter 17. Rio de Janeiro, Brazil: Fiocruz Editorial; 1999. pp. 747-792.

\section{Submit your next manuscript to BioMed Central and we will help you at every step:}

- We accept pre-submission inquiries

- Our selector tool helps you to find the most relevant journal

- We provide round the clock customer support

- Convenient online submission

- Thorough peer review

- Inclusion in PubMed and all major indexing services

- Maximum visibility for your research

Submit your manuscript at www.biomedcentral.com/submit

) Biomed Central 